\title{
Monkeys are Curious about Counterfactual Outcomes
}

\author{
Maya Zhe Wang ${ }^{1,2}$ and Benjamin Y. Hayden ${ }^{2}$ \\ ${ }^{1}$ Department of Brain and Cognitive Sciences and Center for Visual Sciences, \\ University of Rochester, Rochester, NY 14627 \\ ${ }^{2}$ Department of Neuroscience and Center for Magnetic Resonance Research, \\ University of Minnesota, Minneapolis MN 55455
}

Contact Information: 
ABSTRACT

19 While many non-human animals show basic exploratory behaviors, it remains unclear

20 whether any animals possess human-like curiosity. We propose that human-like curiosity satis-

21 fies three formal criteria: (1) willingness to pay (or to sacrifice reward) to obtain information, (2)

22 that the information provides no instrumental or strategic benefit (and the subject understands

23 this), and (3) the amount the subject is willing to pay scales with the amount of information

24 available. Although previous work, including our own, demonstrates that some animals will sac-

25 rifice juice rewards for information, that information normally predicts upcoming rewards and

26 their ostensible curiosity may therefore be a byproduct of reinforcement processes. Here we get

27 around this potential confound by showing that macaques sacrifice juice to obtain information

28 about counterfactual outcomes (outcomes that could have occurred had the subject chosen differ-

29 ently). Moreover, willingness-to-pay scales with the information (Shannon entropy) offered by

30 the counterfactual option. These results demonstrate human-like curiosity in non-human animals

31 according to our strict criteria, which circumvent several confounds associated with less stringent

32 criteria. 


\section{INTRODUCTION}

35 Curiosity is a major driver of exploration and learning. The term curiosity generally re-

36 fers to information-seeking behavior that is intrinsically motivated (Golman \& Loewenstein,

37 2016; Gottlieb, Oudeyer, Lopes, \& Baranes, 2013; Kidd \& Hayden, 2015; Loewenstein, 1994;

38 Oudeyer, Kaplan, \& Hafner, 2007). The intrinsic factor distinguishes curiosity from strategic

39 forms of information seeking, such as exploration in bandit tasks (Daw, O'Doherty, Dayan, Sey-

40 mour, \& Dolan, 2006; Hayden \& Platt, 2009). Thus, a stringent definition of curiosity refers to

41 information seeking that reduces a decision-maker's information gap without producing immedi-

42 ate or even potential reward or strategic benefits (Golman \& Loewenstein, 2015; 2016). By this

43 definition humans are curious (Berlyne, 1966; Gottlieb et al., 2013; Gruber, Gelman, \& Ranga-

44 nath, 2014; Kang et al., 2009; Loewenstein, 1994). For example, many people will pay money to

45 for answers to trivia questions or to solve crossword puzzles even when those answers are pa-

46 tently useless (i.e. trivial, Kang et al., 2009; Gruber, Gelman, \& Ranganath, 2014).

47 Thus we propose a conservative definition for human-like curiosity that requires (1) a

48 willingness to pay for information, (2) the information is strategically useless, and (3) the infor-

49 mation-seeking tendency increases with the amount of information provided (at least up to a

50 point, see Discussion). Is it not clear whether non-human animals possess human-like curiosity

51 according to this conservative definition (Kidd \& Hayden, 2015). Many animals naturally ex-

52 plore their surroundings (Berlyne, 1966). For example, monkeys seek specific information while

53 solving mechanical puzzles without immediate extrinsic motivations (Davis, Settlage, \& Harlow,

54 1950; H. F. Harlow, 1950; H. F. Harlow, Harlow, \& Meyer, 1950). Rats also show spontaneous

55 exploration of unfamiliar maze sections without explicit reward or task (Dember, 1956; Hughes,

56 1968; Kivy, Earl, \& Walker, 1956; Tolman, 1948). However, these information-seeking behav- 
57 iors may be byproducts of natural foraging behavior where exploration or problem solving could

58 lead to food (Emery \& Clayton, 2004; Thorndike, 2017). Indeed, in these contexts, the animal

59 may believe the actions performed could lead directly to reward (Menzel, 1991). Another practi-

60 cal limitation of these studies is the difficulty of formally quantifying the information gap, and

61 thus showing that demand scales with information amount.

62 These problems have motivated scholars to focus on more controlled paradigms. Rigor-

63 ous experiments have quantified information-seeking behavior under controlled conditions in

64 species ranging from Caenorhabditis elegans worms (Calhoun, Chalasani, \& Sharpee, 2014) to

65 rhesus macaques (Averbeck, 2015; Costa, Monte, Lucas, Murray, \& Averbeck, 2016; Noonan et

66 al., 2010; Pearson, Hayden, Raghavachari, \& Platt, 2009; Walton, Behrens, Buckley, Rudebeck,

$67 \&$ Rushworth, 2010; Whittle, 1988). However, information in these tasks generally offers strate-

68 gic benefits that could lead to greater future rewards. Likewise, in some uncertain contexts, ani-

69 mals prefer risky options; these options may be favored because they provide more information

70 (Heilbronner \& Hayden, 2013). Again, however, other non-curiosity-related factors may explain

71 risky choice in these contexts, such as erroneous belief that stochastic processes are actually pat-

72 terned (Blanchard, Wolfe, Vlaev, Winston, \& Hayden, 2014; Hayden \& Platt, 2007).

73 Another paradigm used to demonstrate curiosity has been the temporal resolution of un-

74 certainty paradigm (Blanchard, Hayden, \& Bromberg-Martin, 2015a; Bromberg-Martin \&

75 Hikosaka, 2009; Kidd, Palmeri, \& Aslin, 2013). Many animals will sacrifice small amounts of

76 food to obtain information about upcoming stochastic rewards (sometimes known as observing

77 behavior, Blanchard et al., 2015a; Bromberg-Martin \& Hikosaka, 2009; Bromberg-Martin,

78 Matsumoto, \& Hikosaka, 2010; Gipson, Alessandri, Miller, \& Zentall, 2009; Roper, 1999; Stag-

79 ner \& Zentall, 2010; Zentall \& Stagner, 2011). However, two major factors raise doubt about the 
80 ability of observing behavior tasks to demonstrate curiosity. First, Pavlovian learning may bias

81 instrumental choice actions (Beierholm \& Dayan, 2010; Dayan, Niv, Seymour, \& Daw, 2006).

82 That is, information in these tasks reliably predicts upcoming rewards. In a modified temporal

83 difference learning model, informative cues increases the subjects' engagement. The engagement

84 maintains the representation of subjective value associated with the cue and the states associative

85 with the objective reward. Thus, a non-informative (non-predictive) cue would lead to disen-

86 gagement and a decrease in representation. This model predicts the preference for informative

87 choice due not to the curiosity for information, but to the engaged and maintained representation

88 of predicted value. Another related possibility is that animals may "superstitiously" believe that

89 their choices with information could affect upcoming rewards (Vasconcelos, Monteiro, \& Ka-

90 celnik, 2015).

91 Most of these problems stem from the direct association between information and imme-

92 diate or potential rewards. Therefore, one way to avoid these confounds is to focus on curiosity

93 about counterfactual outcomes. The term counterfactual refers to outcomes associated with op-

94 tions that were not chosen (the terms hypothetical and fictive are also sometimes used, Abe \&

95 Lee, 2011; Hayden, Pearson, \& Platt, 2009). Monkeys can recognize counterfactual outcomes;

96 their responses to counterfactual information indicate that understand its meaning, and do not

97 simply respond as they would to conditioned reinforcers (Abe \& Lee, 2011; Hayden et al., 2009;

98 Rosati \& Hare, 2013). Therefore, counterfactual outcomes can potentially help avoid some prob-

99 lems associated with paradigms in which curiosity-driving information relates to potential re-

100 wards.

$101 \quad$ We devised a counterfactual information task for rhesus macaques. On each trial, sub-

102 jects chose between two gambles with independently generated stakes, probabilities, and coun- 
103 terfactual information status. That is, some options offered, if chosen, the promise of information

104 about the result of the unchosen gamble; other options did not offer that information. We found

105 that monkeys actively sought out information of counterfactual outcome, despite the lack of its

106 instrumental benefits for current or future reward, and their preference for informative options

107 scaled with the amount of information (i.e. Shannon entropy). 


\section{RESULTS}

\section{Monkeys Seek Counterfactual Information}

Two rhesus macaques performed a novel gambling task designed to measure the subjec-

114 tive value placed on information about counterfactual outcomes (Figure 1A and Methods). On

115 each trial of the counterfactual information task, monkeys chose between two gambles (offer 1

116 and offer 2) presented on the left and the right side of the screen. Presentation was asynchronous;

117 order of sides was randomized. Gambles differed in three dimensions: payoff (small: $125 \mathrm{uL}$ of

118 water; medium: $165 \mathrm{uL}$; large: $250 \mathrm{uL}$, indicated by yellow, blue, or green color); probability (0

119 to 1 in 0.01 increments, indicated by bar section height); and informativeness (that is, whether

120 the choice would lead to counterfactual information, indicated by the presence of an inscribed

121 circle, Figure 1A). Payoff, probability, and informativeness were independently randomized for

122 each offer on each trial. On 50\% of the trials, only one option was informative (info choice trials),

123 on $25 \%$ of the trials, both options were informative (forced info trials), and on the remaining

$12425 \%$, neither option was informative (no info trials).

125 We have previously used this general structure (without the informativeness manipula-

126 tion) to probe macaques' preferences for uncertainty and, through various controls, have demon-

127 strated that they treat these as described gambles (Hayden, Heilbronner, \& Platt, 2010; Heil-

128 bronner \& Hayden, 2016). Critically, over the training period before data collection, subjects had

129 ample opportunity to learn that the distribution of both actual outcome and counterfactual out-

130 comes perfectly matched their probabilities. Monkeys' behavior following training suggested

131 that they understood the task. Most importantly, they chose the gamble with larger expected val-

132 ue $82.06 \%$ of the time (subject B: $81.68 \%$; subject J: $82.69 \%$ ). This proportion is larger than ex- 
133 pected by chance (both subjects: $\mathrm{X}^{2}=1865$; $\mathrm{P}<0.001$; subject $\mathrm{B}$ : $\mathrm{X}^{2}=1133$; $\mathrm{P}<0.001$; subject J:

$134 \quad \mathrm{X}^{2}=729.83 ; \mathrm{P}<0.001 ;$ chi-square test).

135 Monkeys preferred gambles that provided counterfactual information. To measure the ef-

136 fect of counterfactual information on choice, we used a multiple logistic regression model to fit

137 the probability of choosing offer 1 as a function of four variables, the expected values and in-

138 formativeness of the two offers. The probability of choosing offer 1 was positively predicted by

139 expected value of offer $1(\mathrm{~B}=0.0283, \mathrm{SE}=0.0007$, $\mathrm{t}-\mathrm{stat}=38.94 ; \mathrm{P}<0.001$; Figure $2 \mathrm{~A}-\mathrm{C})$ and

140 negatively predicted by that of offer $2(B=-0.0270, S E=0.0007$, t-stat $=-37.50 ; \mathrm{P}<0.001)$. By in-

141 cluding informativeness in the same model, it competed with expected values to explain variance

142 in behavior. We found that informativeness predicted choice above and beyond the effect of ex-

143 pected value. Specifically, the probability of choosing offer 1 was positively predicted by its in-

144 formativeness $(\mathrm{B}=0.2633, \mathrm{SE}=0.0616$, $\mathrm{t}-\mathrm{stat}=4.27 ; \mathrm{P}<0.001 ;$ logistic regression $)$ and negatively

145 predicted by the informativeness of offer $2(B=-0.2042, S E=0.0615, t-s t a t=-3.32 ; P=0.001$; lo-

146 gistic regression). This result shows that monkeys were more likely to choose options with larger

147 expected value and that provide counterfactual information.

\section{Preference for counterfactual information scales with information}

Observing the outcome of a gamble reduces uncertainty about the observed outcome and

151 thus provides information in a formal sense (Cover \& Thomas, 2006; MacKay, 2003; Shannon \&

152 Weaver, 2015). The amount of information, or entropy, provided by revealing a gamble outcome

153 is not constant for all gamble probabilities. Instead, entropy, gained from revealing a gamble

154 outcome peaks at probability of 0.5 , when the outcome is most uncertain, and decreases lawfully

155 as probability moves closer to 0 or 1 , when the outcome gets more certain (Figure 1 B; Cover \& 
156 Thomas, 2006; MacKay, 2003; Shannon \& Weaver, 2015). Therefore, to satisfy our proposed

157 definition of curiosity, subjects' willingness-to-pay for counterfactual information should scale

158 with the option's entropy.

We defined the informational value (IV) of each gamble as the entropy of the chosen gamble when the chosen gamble was not informative and as the sum of entropy of both the cho-

161 sen and unchosen gambles when the chosen gamble was informative (Equation 2-4; see Meth-

ods). We then used a multiple logistic regression model to fit the probability of choosing offer 1

163 as a function of expected values and informational values of the two offers. Note, critically, that

164 we use the term informational value differently than informativeness, which is the binary varia-

165 ble we used in the previous section. Informational value refers to entropy, which is a continuous

166 variable. Informativeness and informational value are orthogonal in our task because of the fully

167 independently randomized probabilities for both options.

168 A logistic regression analysis that included informational value instead of informative-

169 ness revealed, first (not surprisingly), that monkeys preferred the higher value options. Specifi-

170 cally, probability of choosing offer 1 is positively predicted by the expected value of offer 1

$171(\mathrm{~B}=0.0281, \mathrm{SE}=0.0007, \mathrm{t}-\mathrm{stat}=38.90 ; \mathrm{P}<0.001 ;$ Figure $2 \mathrm{D}-\mathrm{F})$ and negatively predicted by that

172 of offer $2(\mathrm{~B}=-0.0268 ; \mathrm{SE}=0.0007$; t-stat=-37.29; $\mathrm{P}<0.001)$. Second, and critically, the probabil-

173 ity of choosing offer 1 was positively predicted by its informational value $(B=0.3536$;

$174 \mathrm{SE}=0.0653 ; \mathrm{t}-\mathrm{stat}=5.42 ; \mathrm{P}<0.001 ;)$ and negatively predicted the informational value of offer 2

$175(\mathrm{~B}=-0.2773 ; \mathrm{SE}=0.0650 ; \mathrm{t}-\mathrm{stat}=-4.26 ; \mathrm{P}<0.001)$. Thus, informational value explained a signifi-

176 cant portion of variance in choice behavior, above and beyond that was explained by expected

177 values. These results demonstrate that monkeys preferred options that provided higher entropy, 
178 and thus larger amount of information. Therefore, monkeys' information-seeking tendency

179 scaled with the amount of information provided.

180

181

182

183

184

185

186

187

188

189

190

191

192

193

194

195

196

197

198

199

200

\section{Monkeys prefer information, not the visual stimuli}

One possible alternative explanation for monkeys' preference is that they seek the options

that have or that lead to more visual stimuli, which in this task are the informative options (Roper, 1999). To rule out this possibility, we conducted the following two analyses.

First, we entered expected value, informativeness (binary variable), and informational value (entropy associated with a choice) simultaneously into a multiple logistic regression

(Equation 6; see Methods). Because informativeness was perfectly correlated with both presented and expected additional visual stimuli, this analysis allows the presence of additional visual stimuli and informational value to directly compete for explaining variance in choices. As

before, we found that probability of choosing offer 1 is positively predicted by the expected value of offer $1(\mathrm{~B}=0.0281, \mathrm{SE}=0.0007$, $\mathrm{t}-\mathrm{stat}=38.74 ; \mathrm{P}<0.001$; Figure 2G) and negatively predicted by that of offer $2(\mathrm{~B}=-0.0268 ; \mathrm{SE}=0.0007 ; \mathrm{t}-\mathrm{stat}=-37.05 ; \mathrm{P}<0.001 ;)$. Crucially, the probability of choosing offer 1 was not significantly predicted by the informativeness (i.e. presence of additional visual stimuli) of either offer $1(\mathrm{~B}=-0.0248 ; \mathrm{SE}=0.1190 ; \mathrm{t}-\mathrm{stat}=-0.21 ; \mathrm{P}=0.835)$ or offer 2 $(\mathrm{B}=0.0312 ; \mathrm{SE}=0.1193 ; \mathrm{t}-\mathrm{stat}=0.26 ; \mathrm{P}=0.794)$. And yet, it was positively predicted by its informational value $(B=0.3822 ; \mathrm{SE}=0.1348 ; \mathrm{t}-\mathrm{stat}=2.84 ; \mathrm{P}=0.005 ;$ logistic regression $)$ of offer 1 and negatively predicted the informational value of offer $2(B=-0.3095 ; S E=0.1343$; t-stat $=-2.31$; $\mathrm{P}=0.021$; logistic regression). These results indicate that the additional visual stimuli did not significantly account for variance in the behavior. It is the Shannon information, not the additional visual stimuli associated with informative options per se that drives preference. 

seek more information, then using informational value, instead of informativeness, in the multiple logistic regression would yield a better fit to the choice behavior. Akaike information criteri-

204 on (AIC) is one of the common measurements for formal model comparison. We found the mod-

205 el incorporating entropy resulted in a smaller AIC score $(\mathrm{AIC}=6571.97)$ than the previously de-

206 scribed model $(\mathrm{AIC}=6580.22)$, indicating a better fit to the data. AIC weight estimates the rela-

207 tive likelihood of a particular model among all the candidate models, and thus provides a quanti-

208 tative measure of how much better a model is to the alternative(s) (Burnham \& Anderson, 2010).

209 Comparing these two AIC values, the model incorporating entropy resulted in an AIC weight of

$21098.41 \%$, which means that this model is $98.41 \%$ more likely to be the one that resembles the true

211 data-generating model, and thus better describing the choice behavior (this percent roughly trans-

212 lates to $\mathrm{P}=0.016$ in traditional significance test; Equation 7; see Methods). These results further

213 confirm that monkeys' preferences for the informative gamble was driven by its informational

214 value, i.e. entropy, rather than driven by potential confounds, such as total visual stimuli on the

215 screen.

Although counterfactual information in our task provided no strategic benefit due to trial-

219 to-trial independency, we wondered whether monkeys nonetheless acted as if it did; if so they

220 might have adjusted their strategy after receiving counterfactual information (Hayden et al.,

221 2009). We thus examined changes in preference resulting from counterfactual information.

222 Choice accuracy (likelihood of choosing the option with the greater expected value) did not

223 measurably change after receiving counterfactual outcome information. Specifically, it was 
$22481.48 \%(n=4227)$ when the counterfactual outcome was revealed and $82.68 \%(n=3914)$ when it 225 was not $\left(\mathrm{X}^{2}=1.99 ; \mathrm{P}=0.158\right.$; chi-square test $)$.

The valence of counterfactual information also did not measurably affect subsequent

227 choices. Counterfactual information could potentially lead to either a good news condition (cho-

228 sen gamble win and unchosen gamble loss, or, chosen win $>$ unchosen win), or a bad news con-

229 dition (chosen gamble loss and unchosen gamble win, or, chosen loss $>$ unchosen loss). We

230 found no difference in subsequent choice accuracy following a good news condition (82.57\%)

231 versus a bad news condition $(81.02 \% ; \mathrm{X} 2=2.24 ; \mathrm{P}=0.134$; chi-square test). Moreover, a bad news

232 condition (possibly leading to a regret-like state) did not motivate choice of the unchosen side

$233\left(\mathrm{X}^{2}=0.05 ; \mathrm{P}=0.818\right.$; chi-square test $)$ or original position $\left(\mathrm{X}^{2}=0.07 ; \mathrm{P}=0.789\right.$; chi-square test $)$ rela-

234 tive to a good news condition, and thus ruling out win-stay-lose-shift strategy based on counter-

235 factual information. We also found no difference in subsequent information-seeking tendency

236 following a good new condition versus a bad news condition $\left(53.46 \%\right.$ versus $52.45 \%$; $\mathrm{X}^{2}=0.26$;

$237 \mathrm{P}=0.609$; chi-square test). These results show that counterfactual information did not lead to

238 measurable choice strategy shifts and argue against the possibility that our effects reflect errone-

239 ous belief by our subjects about the meaning of the signals they see.

243 chometric curves showing probability of choosing the informative gamble as a function of ex-

244 pected value difference between informative and non-informative gambles (Figure 2H). This

245 curve was shifted to the left, indicating that monkeys sacrificed water reward for information. On

246 average, they sacrificed $6.40 \mathrm{uL}$ of water reward (subject B: $6.41 \mathrm{uL}$; subject J: $6.37 \mathrm{uL}$ ) relative 
247 to a pure reward-maximizing strategy ( $\mathrm{t}-\mathrm{stat}=4.87 ; \mathrm{P}<0.001$; $\mathrm{t}$-test), to gain 0.014 bits (subject $\mathrm{B}$ :

2480.0147 bits; subject J: 0.0135 bits) more information. This water payment for information is

$2495.32 \%$ the size of the average reward obtained per trial. Thus, monkeys sacrificed a small but

250 significant amount of primary reward to satisfy their curiosity about the counterfactual outcomes. 


\section{DISCUSSION}

We find that when choosing between risky options, macaques prefer gambles that prom-

254 ise information about what would have occurred had they chosen differently. This information,

255 known as counterfactual information, has no direct or indirect benefits and provides no infor-

256 mation about the statistics of the current task environment. Indeed, we see no measurable effect

257 of counterfactual outcomes on strategic adjustments. As such our task satisfies the three strict

258 criteria we propose for human-like curiosity in non-human animals: (1) a willingness to pay for

259 information that (2) gives no strategic benefit and (3) the willingness to pay scales with amount

260 of information available.

261 Many non-human animals will explore new environments or stimuli (Kidd \& Hayden,

262 2015). Although exploratory behaviors may reflect curiosity, it is hard to ascertain whether they

263 reflect a drive for information per se. For this reason, many scholars favor more controlled para-

264 digms. Many of these use observing behavior - a preference to reduce uncertainty about stochas-

265 tic upcoming rewards. Observing behavior has been shown in numerous species; however, pre-

266 vious results have not established that the observing behavior scales with entropy (Badia, Ryan,

267 \& Harsh, 1981; R. Blanchard, 1975; Blanchard et al., 2015a; Bromberg-Martin et al., 2010;

268 Dinsmoor, Mulvaney, \& Jwaideh, 1981; Lieberman, 1972; Prokasy, 1956; Purdy \& Peel, 1988;

269 Roper, 1999; Steiner, 1967; Wilton \& Clements, 1971; Wyckoff, 1952). Due to this lack of sup-

270 port from formal information theory, observing behavior suffer from a potential confound with

271 Pavlovian learning processes (Beierholm \& Dayan, 2010; Dayan et al., 2006; Roper, 1999).

272 In this light, another potential limitation is the possibility that seemingly information-

273 seeking behaviors could have been a byproduct of other processes. One such process is when in- 
274 formation gained is a byproduct as animals explore and manipulate the environment to acquire

275 reward (Emery \& Clayton, 2004; Thorndike, 2017). Another example is that information seeking

276 leads to learning of the structure of a task and thus to strategic benefits (Daw et al., 2006; Doll,

277 Duncan, Simon, Shohamy, \& Daw, 2015; Noonan et al., 2010; Walton et al., 2010). Yet another

278 case is that information could be misconceived as influencing the likelihood of reward (Heil-

279 bronner \& Hayden, 2013; Vasconcelos et al., 2015). In all cases, information is acquired not for

280 the gain of information but for the gain of other perceived instrumental benefits.

281 In the current task, we provided subjects with the opportunity to actively choose to reveal

282 counterfactual outcomes, even at the cost of primary rewards. Due to the cross-trial independent

283 design, counterfactual information provides neither immediate or future rewards, nor actual or

284 perceived strategic benefits. The lack of strategic adjustment after receiving counterfactual in-

285 formation in our subjects confirmed the effectiveness of this manipulation. Importantly, animals'

286 willingness to pay scaled with the amount of information. This result reflects the idea that curios-

287 ity must necessarily be a drive for information. That is, to use Loewenstein's term, it resolves an

288 information gap between current knowledge and potential knowledge (Golman \& Loewenstein,

289 2015; 2016; Gruber et al., 2014; Loewenstein, 1994). Therefore, our results bridged the theoreti-

290 cal and empirical findings with formal information theory to show human-like curiosity in non-

291 human primates.

Our formal criteria for curiosity include a requirement that amount of curiosity scales

293 with amount of information available. This criterion is important because it explicitly links os-

294 tensible curiosity behavior to an information gap per se. It also provides a ready control for rein-

295 forcement processes, such as engagement to cues and tracking of conditioned reinforcers. Note

296 that, formally speaking, we only require a positive relationship between entropy and willingness 
297 to pay along a subset of possible values. Our criteria allow future research the possibility for

298 more complex relationship along a full range. For example, it is likely that demand form infor-

299 mation eventually saturates and even decreases as entropy rises (Kidd, Piantadosi, \& Aslin,

$300 \quad 2012 ; 2014)$.

301 These results have direct implications for neuroscientific research. The goal of under-

302 standing curiosity is important for its role in driving choice and learning in uncertain environ-

303 ments (Kidd \& Hayden, 2015). We offer a well-controlled paradigm for isolating curiosity from

304 potential confounds separating it from seemingly similar factors. One neuroscientific problem

305 that could benefit from our result is how curiosity influences learning and reward processes. Par-

306 ticularly, understanding how prospective and received values of information outcome and prima-

307 ry reward outcome are represented, and how curiosity or value of information influences learning

308 and update of model-free and model-based processes, across prefrontal, striatal, and ventral teg-

309 mental areas, would start to reveal how curiosity could serve as an intrinsic drive to shape an or-

310 ganism's learning and decision-making (Chang, Gardner, Di Tillio, \& Schoenbaum, 2017; Fa-

311 rovik et al., 2015; Gershman \& Schoenbaum, 2017; Howard \& Kahnt, 2017; Kahnt, Heinzle,

312 Park, \& Haynes, 2010; Langdon, Sharpe, Schoenbaum, \& Niv, 2018; Sadacca et al., 2018; Stal-

313 naker, Liu, Takahashi, \& Schoenbaum, 2018; Takahashi et al., 2017; Wang \& Hayden, 2017). 


\section{Figures and Figure Captions}

1A. The Counterfactual Information Task.

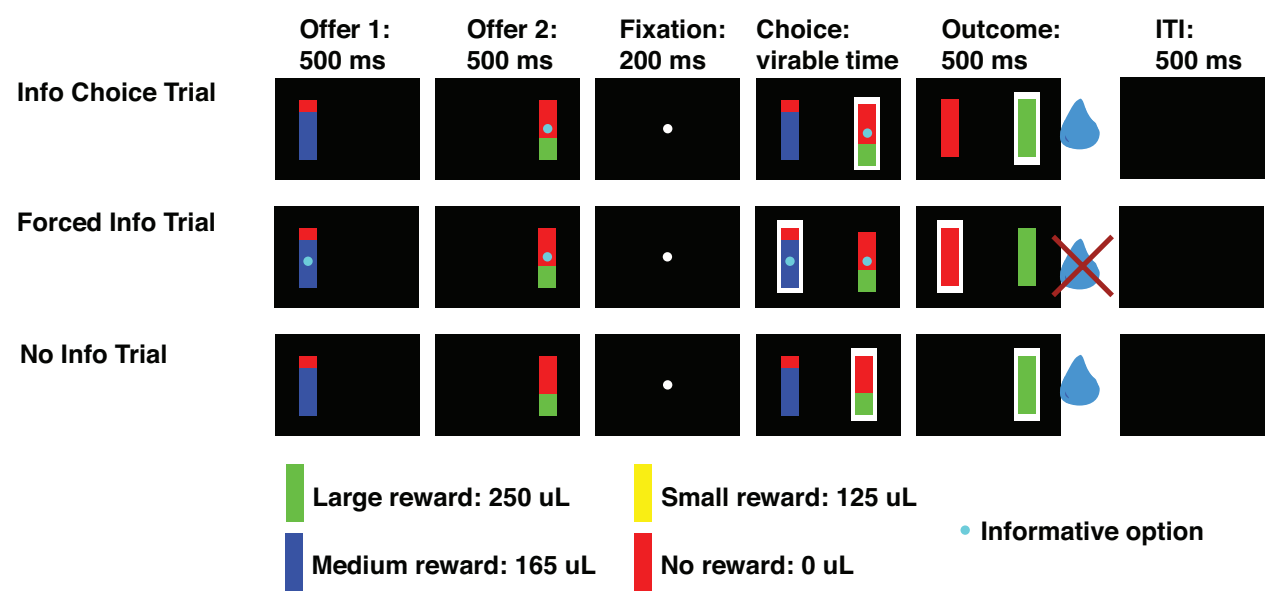

Figure 1 B. Entropy of Probablistic Outcomes.

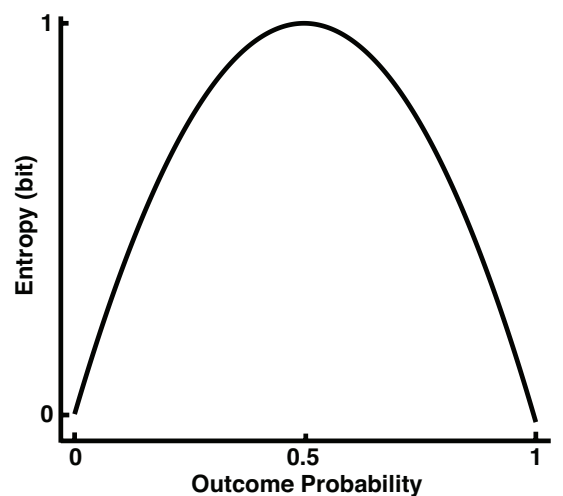

Outcome Probability

Figure 1. (A)The Counterfactual Information Task. Trial starts with serial presentation of of-

321 fer 1 and offer 2, followed by a central fixation, choice, outcome, and an intertrial interval. The

322 color of the offer indicates the size of the reward payoff and the height indicates the probability

323 of receiving the payoff. The cyan dot at the center of the offers indicates the informativeness of

324 an offer. Outcome is indicated following choice by filling the offer rectangle with the payoff col-

325 or. Upon choice, payoff of the chosen gamble is delivered while the outcome is revealed. The

326 informative option will lead to the reveal of both chosen and unchosen gamble outcomes. The

327 non-informative option will lead to the reveal of only the chosen gamble outcome. On $50 \%$ of

328 the trials, only one option was informative (info choice trials), on $25 \%$ of the trials, both options 
329 were informative (forced info trials), and on the rest, neither gamble was informative (no info

330 trials). (B) Entropy of Probabilistic Outcomes. Entropy, information gained from revealing a

331 gamble outcome, peaks at probability of 0.5 , when the outcome is most uncertain, and decreases

332 lawfully as probability moves closer to 0 or 1 , when the outcome gets more certain. 
bioRxiv preprint doi: https://doi.org/10.1101/291708; this version posted March 29, 2018. The copyright holder for this preprint (which was not certified by peer review) is the author/funder, who has granted bioRxiv a license to display the preprint in perpetuity. It is made available under aCC-BY-NC-ND 4.0 International license.

Figure 2. Results.

2A. Informativeness Predicted Choice: Both Subjects.

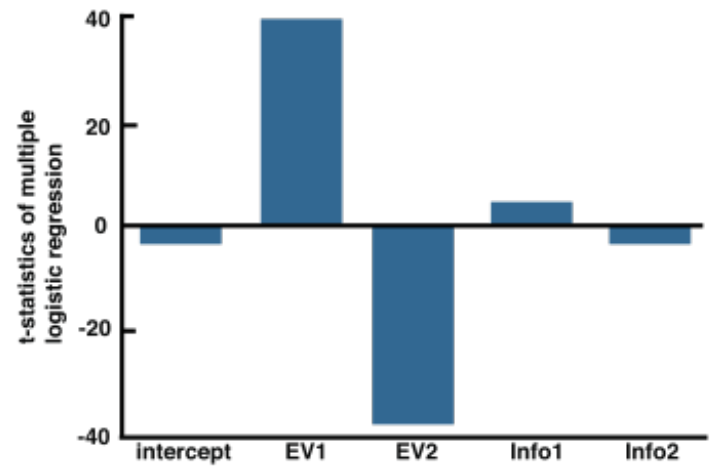

2D. Informational Value Predicted Choice: Both Subjects.

2B. Informativeness Predicted Choice: Subject B.
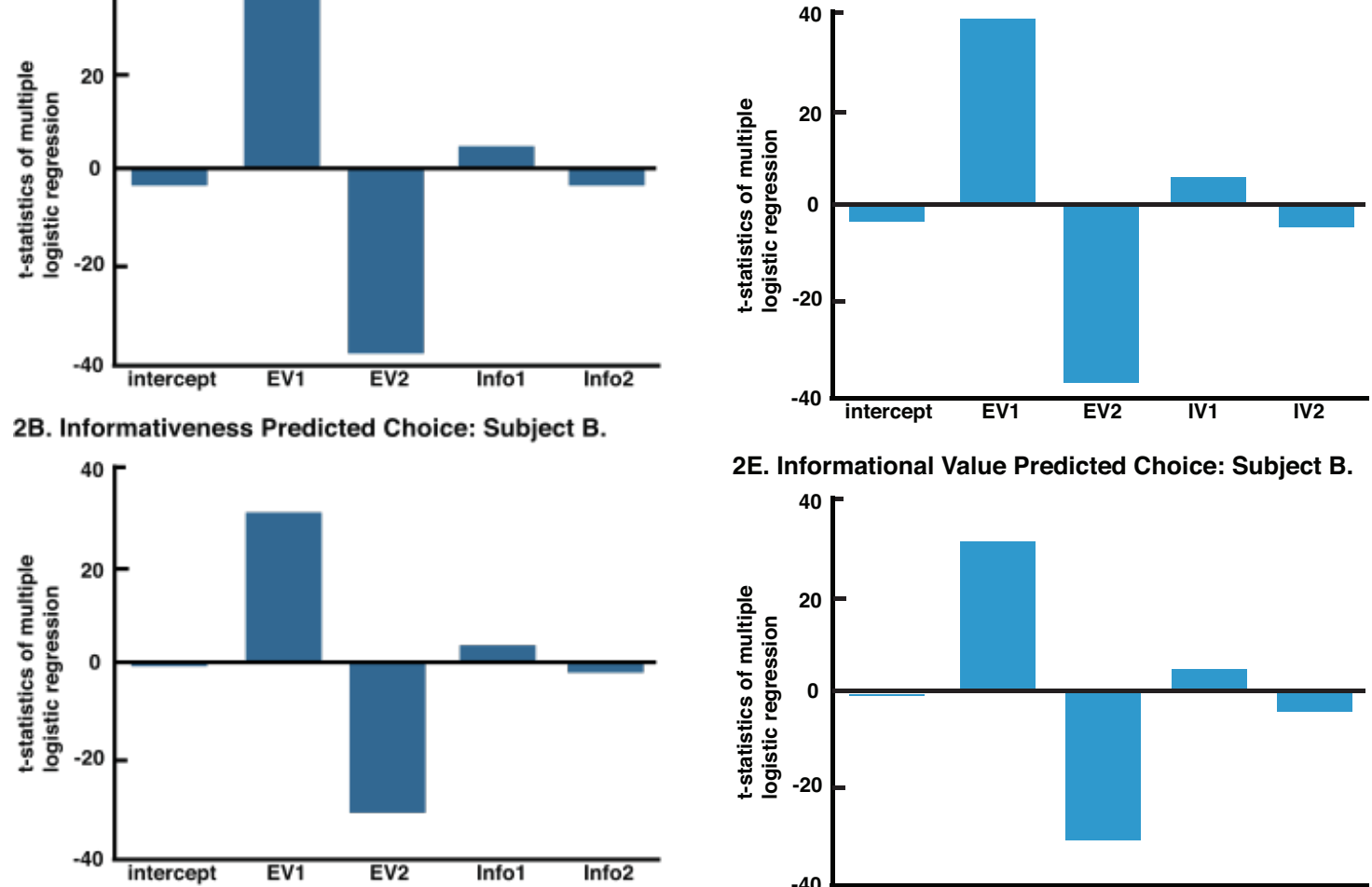

2E. Informational Value Predicted Choice: Subject B.

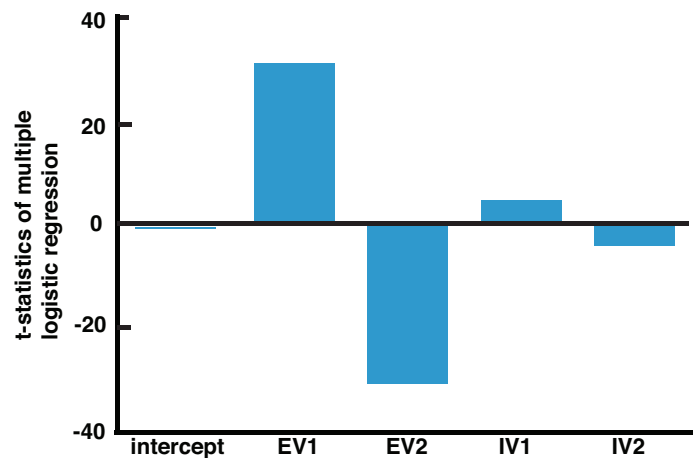

2C. Informativeness Predicted Choice: Subject J.

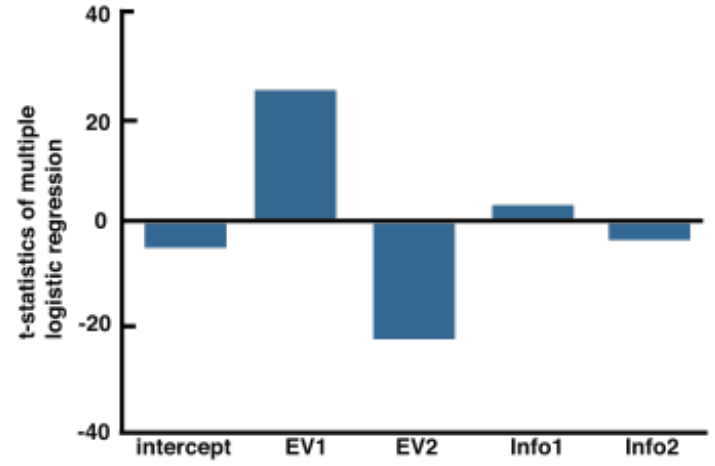

2F. Informational Value Predicted Choice: Subject J.

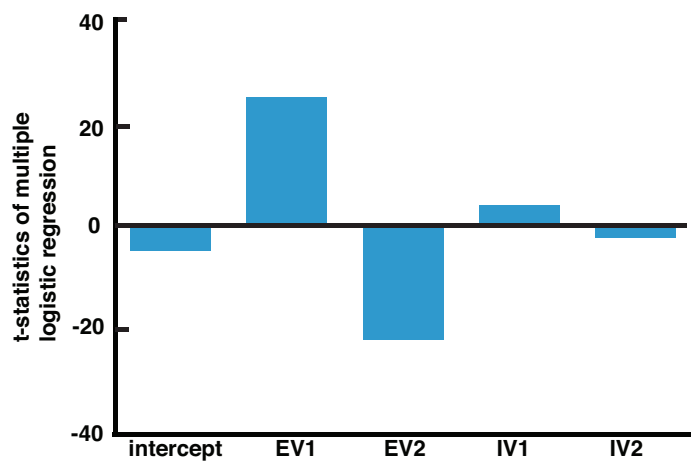


2G. Informational Value not Visual Stimuli Predicts Choice.

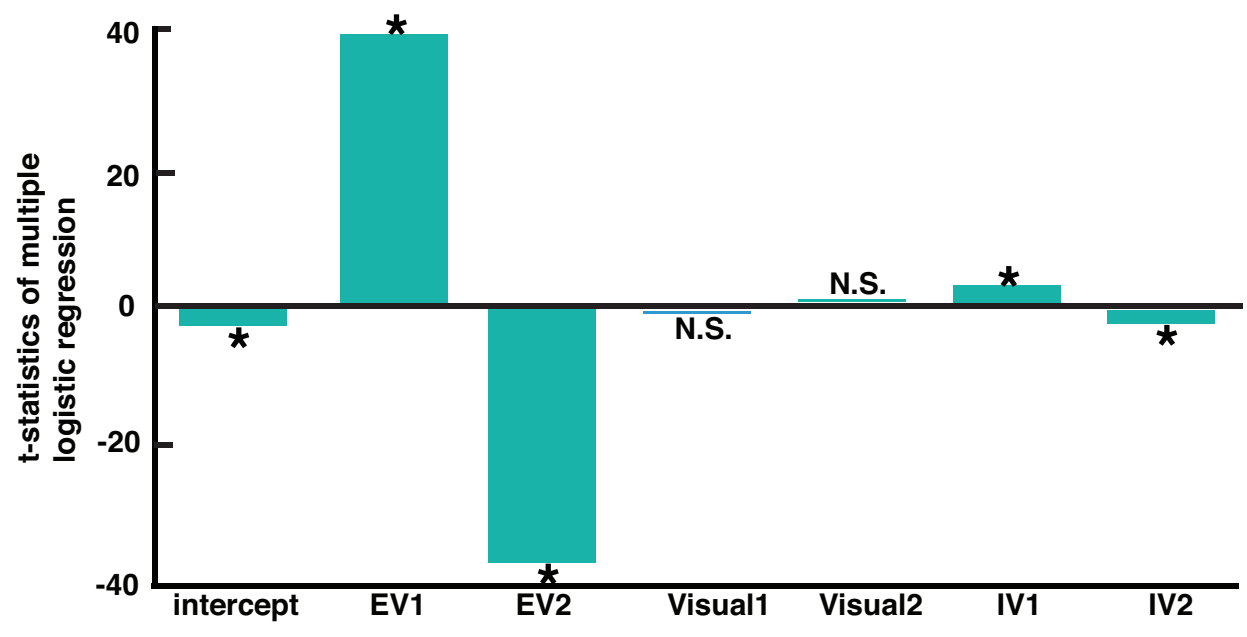

2H. Counterfactual Information Was Subjectively Valuable.

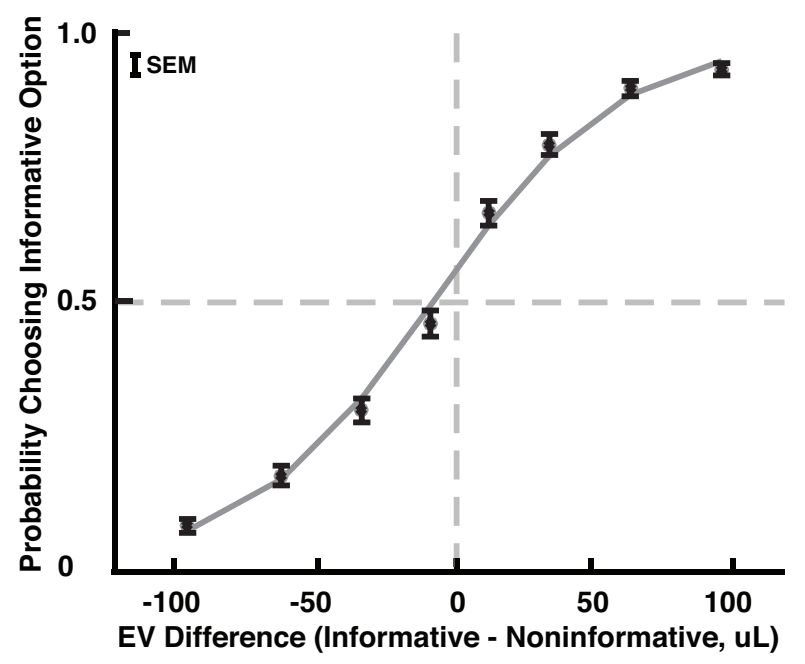

Figure 2. (A-G) X-axis: predictors included in the multiple logistic regression. Y-axis: t-

341 statistics of each predictor. (A-C) Probability of choosing offer 1 as a function of expected val-

342 ues (EV) and informativeness (info) of offer 1 and offer 2, fitted for both subjects and each sub-

343 ject. (D-F) Probability of choosing offer 1 as a function of expected values (EV) and informa-

344 tional value (IV) of offer 1 and offer 2, fitted for both subjects and each subject. (G) Probability

345 of choosing offer 1 as a function of expected values (EV), informativeness visual cues (visual),

346 and informational value (IV) of offer 1 and offer 2 . Asterisk: significant $(p<0.05)$. N.S.: not sig-

347 nificant. (H) Fitted logistic curve for probability of choosing informative option as a function of 
348 value difference (expected value of informative option minus expected value of non-informative

349 option). The leftward shift shows the higher subjective value placed on informative options. 


\section{METHODS}

\section{General Methods}

All animal procedures were approved by the University of Rochester Animal Care and

355 Use Committee and were conducted in compliance with the Public Health Service's Guide for

356 the Care and Use of Animals. Two male rhesus macaques (Macaca mulatta), aged 9-10 years

357 and weighting 8.0-9.9 kg served as subjects. Both subjects had extensive previous experience in

358 risky decision-making tasks. Subjects had full access to food (LabDiet 5045, ad libitum) while in

359 their home cages. Subjects received at minimum $20 \mathrm{~mL}$ per $\mathrm{kg}$ of water per day, although in

360 practice they received close to double this amount in the lab as a result of our experiments. No

361 subjects were sacrificed as a result of these experiments, nor were they physically harmed.

362 Visual stimuli were colored rectangles on a computer monitor (see Figure 1). Stimuli

363 were controlled by Matlab with Psychtoolbox and Eyelink Toolbox. A solenoid valve controlled

364 the delivery duration of fluid rewards. Eye positions were sampled at 1,000 $\mathrm{Hz}$ by an infrared

365 eye-monitoring camera system (SR Research, Osgoode, ON, Canada). A small mount was used

366 to facilitate maintenance of head position during performance.

367 Subjects had never previously been exposed to decision-making tasks in which counter-

368 factual information was available. Previous training history for these subjects included two types

369 of foraging tasks (T. C. Blanchard \& Hayden, 2015; T. C. Blanchard, Strait, \& Hayden, 2015b),

370 intertemporal choice tasks (Hayden, 2016), two types of gambling tasks (Azab \& Hayden, 2017;

371 Strait, Blanchard, \& Hayden, 2014), and two types of reward-based decision tasks(Sleezer,

372 Castagno, \& Hayden, 2016; Wang \& Hayden, 2017).

373 The Counterfactual Information Task 
Two subjects (B and $\mathrm{J}$ ) performed a novel task designed to measure preference for coun-

375 terfactual information (Figure 1A). On each trial subjects chose between two randomly selected

376 gambles, presented asynchronously on the left and the right side of the screen. Gambles were

377 represented as rectangular visual stimuli and differed in three dimensions: payoff, probability,

378 and informativeness. Payoff came in three sizes, small (125 microliters), medium (165 micro-

379 liters), and large (250 microliters), each corresponding to a yellow, blue, and green portion of the

380 rectangle. Probabilities were randomly drawn from a uniform distribution between 0 and 1 (step

381 size of 0.01 ). The height of a portion of the rectangle with a payoff color indicated probability of

382 winning the gamble and the height of the red portion indicated the probability of losing the gam-

383 ble (that is, of receiving no reward for that trial). Informativeness of a gamble was indicated by a

384 cyan dot on the center of the rectangle for an informative option and the lack of a cyan dot for a

385 non-informative one. The informative option promised valid information about the payoff that

386 would have occurred had the alternative option been chosen. On 50\% of the trials, only one op-

387 tion was informative, on $25 \%$ of trials, both gambles were informative, and on the remaining

$38825 \%$ of trials, neither gamble was informative. Probability, payoff, and informativeness were in-

389 dependently randomized on each trial.

Each trial started with the appearance of offer $1(500 \mathrm{~ms})$ followed by a blank $500 \mathrm{~ms}$ de-

391 lay. Offer 1 position was randomized for each trial. Then offer 2 appeared on the other side of

392 the screen $(500 \mathrm{~ms})$ followed by another $500 \mathrm{~ms}$ delay. After a $200 \mathrm{~ms}$ fixation, both gambles

393 appeared on the screen and subjects chose the preferred option by shifting gaze to it and main-

394 taining that gaze for $200 \mathrm{~ms}$. Subsequently, if an informative option was chosen, gamble results

395 for both offers were resolved. If a non-informative option was chosen, gamble results for only

396 the chosen offer was resolved. Resolution of a gamble involved filling the gamble rectangle with 
397 the payoff color, while delivering a water reward, if the gamble result was win, or filling the

398 gamble rectangle with red color, while delivering no reward, if otherwise. This outcome epoch

399 lasted for $800 \mathrm{~ms}$ and was followed by a $1000 \mathrm{~ms}$ inter-trial interval (ITI) and then the start of

400 next trial.

401

402

\section{Statistical Methods}

403

All choices were counted as correct when subjects selected an option with expected value

404 greater than or equal to the non-chosen alternative. Chi-square test was conducted using R. Sub-

405 jects' choice behavior was fitted using a multiple logistic regression model and was conducted

406 using MATLAB (Mathworks). T-test was also carried out with MATLAB.

407 A logistic regression was fitted to choice to assess whether subjects preferred informative 408 option, above and beyond the effect of expected value:

$$
\log \left(\frac{p(\text { choice })}{1-p(\text { choice })}\right)=B_{0}+B_{1} \cdot E V_{1}+B_{2} \cdot E V_{2}+B_{3} \cdot \operatorname{Info} o_{1}+B_{4} \cdot \operatorname{Info} o_{2}
$$

EV stands for expected value, which is the product of reward magnitude and reward

411 probability. Info is 1 when choice of an option leads to resolution of both chosen and unchosen

412 gambles and is 0 when it leads to the resolution of only the chosen gamble.

413 To quantify the amount of information provided when a gamble outcome is resolved, we

414 calculated the "information value" (IV) of each option. The IV is the uncertainty about the possi-

415 ble outcomes that will be eliminated by either observing the outcome or receiving information:

416 the Shannon entropy $(\mathrm{H})$ of the offer:

$$
H(\text { offer })=-\sum_{i \in 0,1} p(\text { outcome }=i) \cdot \log (p(\text { outcome }=i) \text {. }
$$

$418 \quad \mathrm{P}$ is the reward probability associated with a gamble option.

419 When the non-informative offer is chosen, the informational value (IV) of this choice is: 


$$
I V=H\left(\text { offer }_{\text {chosen }}\right) \text {. }
$$

When the informative offer is chosen, the informational value (IV) of this choice is:

$$
I V=H\left(\text { offer }_{\text {chosen }}\right)+H\left(\text { offer } r_{\text {unchosen }}\right) .
$$

424 choice with higher informational value, above and beyond the effect of expected value:

$$
\log \left(\frac{p(\text { choice })}{1-p(\text { cho ce })}\right)=B_{0}+B_{1} \cdot E V_{1}+B_{2} \cdot E V_{2}+B_{3} \cdot I V_{1}+B_{4} \cdot I V_{2}
$$

428 ance in choice:

$$
\log \left(\frac{p(\text { choice })}{1-p(\text { choice })}\right)=B_{0}+B_{1} \cdot E V_{1}+B_{2} \cdot E V_{2}+B_{3} \cdot \text { Visual }_{1}+B_{4} \cdot \text { Visual }_{2}+B_{5} \cdot I V_{1}+
$$

$$
B_{6} \cdot I V_{2}
$$

For model comparison, AIC weights was calculated as following:

$$
w_{i}(A I C)=\frac{\exp \left(-\frac{1}{2}\left(A I C_{i}-A I C_{\min }\right)\right)}{\sum_{r=1}^{m} \exp \left(-\frac{1}{2}\left(A I C_{r}-A I C_{\min }\right)\right)},(i=1,2, \ldots, m) .
$$

434 close to the true data-generating model (Burnham \& Anderson, 2010).

\section{Data Availability}

The datasets generated during the current study are available on the Hayden lab website,

438 http://www.haydenlab.com/, or from the authors on reasonable request. The analyses code gen439 erated during the current study is available from the corresponding author on reasonable request. 
442 B.Y.H and M.Z.W designed the experiment, M.Z.W conducted the experiment and analyzed the

443 data, B.Y.H and M.Z.W wrote the paper.

444

445 Acknowledgements:

446 We thank Shannon Cahalan, Marcelina Martynek, and Michelle Ficalora for help with data col-

447 lection and Becket Ebitz for useful comments on the manuscript. This research was supported by

448 a grant to B.Y.H from NIH R01 DA037229.

449 
Abe, H., \& Lee, D. (2011). Distributed Coding of Actual and Hypothetical Outcomes in the Orbital and Dorsolateral Prefrontal Cortex. Neuron, 70(4), 731-741. http://doi.org/10.1016/j.neuron.2011.03.026

Averbeck, B. B. (2015). Theory of choice in bandit, information sampling and foraging tasks. PLoS Computational Biology, 11(3), e1004164.

Azab, H., \& Hayden, B. Y. (2017). Correlates of decisional dynamics in the dorsal anterior cingulate cortex. PLoS Biology, 15(11), e2003091.

Badia, P., Ryan, K., \& Harsh, J. (1981). Choosing schedules of signaled appetitive events over schedules of unsignaled ones. Journal of the Experimental Analysis of Behavior, 35(2), 187195.

Beierholm, U. R., \& Dayan, P. (2010). Pavlovian-instrumental interaction in 'observing behavior'. PLoS Computational Biology, 6(9), e1000903. http://doi.org/10.1371/journal.pcbi.1000903

Berlyne, D. E. (1966). Curiosity and exploration. Science, 153(3731), 25-33.

Blanchard, R. (1975). The effect of S- on observing behavior. Learning and Motivation, 6(1), 110.

Blanchard, T. C., \& Hayden, B. Y. (2015). Monkeys are more patient in a foraging task than in a standard intertemporal choice task. PLoS ONE, 10(2), e0117057.

Blanchard, T. C., Hayden, B. Y., \& Bromberg-Martin, E. S. (2015a). Orbitofrontal cortex uses distinct codes for different choice attributes in decisions motivated by curiosity. Neuron, 85(3), 602-614. http://doi.org/10.1016/j.neuron.2014.12.050

Blanchard, T. C., Strait, C. E., \& Hayden, B. Y. (2015b). Ramping ensemble activity in dorsal anterior cingulate neurons during persistent commitment to a decision. Journal of Neurophysiology, 114(4), 2439-2449.

Blanchard, T. C., Wolfe, L. S., Vlaev, I., Winston, J. S., \& Hayden, B. Y. (2014). Biases in preferences for sequences of outcomes in monkeys. Cognition, 130(3), 289-299. http://doi.org/10.1016/j.cognition.2013.11.012

Bromberg-Martin, E. S., \& Hikosaka, O. (2009). Midbrain Dopamine Neurons Signal Preference for Advance Information about Upcoming Rewards. Neuron, 63(1), 119-126. http://doi.org/10.1016/j.neuron.2009.06.009

Bromberg-Martin, E. S., Matsumoto, M., \& Hikosaka, O. (2010). Dopamine in motivational control: rewarding, aversive, and alerting. Neuron, 68(5), 815-834. http://doi.org/10.1016/j.neuron.2010.11.022

Burnham, K. P., \& Anderson, D. R. (2010). Model selection and multimodel inference: a practical information-theoretic approach. Springer Science \& Business Media.

Calhoun, A. J., Chalasani, S. H., \& Sharpee, T. O. (2014). Maximally informative foraging by Caenorhabditis elegans. eLife, 3, e04220.

Chang, C. Y., Gardner, M., Di Tillio, M. G., \& Schoenbaum, G. (2017). Optogenetic blockade of dopamine transients prevents learning induced by changes in reward features. Curbio, 27(22), 3480-3486. e3.

Costa, V. D., Monte, O. D., Lucas, D. R., Murray, E. A., \& Averbeck, B. B. (2016). Amygdala and Ventral Striatum Make Distinct Contributions to Reinforcement Learning. Neuron, 92(2), 505-517. http://doi.org/10.1016/j.neuron.2016.09.025

Cover, T. M., \& Thomas, J. A. (2006). Elements of Information Theory 2nd Edition (Wiley Series in Telecommunications and Signal Processing). 
Davis, R. T., Settlage, P. H., \& Harlow, H. F. (1950). Performance of normal and brain-operated monkeys on mechanical puzzles with and without food incentive. The Pedagogical Seminary and Journal of Genetic Psychology, 77(2), 305-311.

Daw, N. D., O'Doherty, J. P., Dayan, P., Seymour, B., \& Dolan, R. J. (2006). Cortical substrates for exploratory decisions in humans. Nature, 441(7095), 876-879. http://doi.org/10.1038/nature04766

Dayan, P., Niv, Y., Seymour, B., \& Daw, N. D. (2006). The misbehavior of value and the discipline of the will. Neural Networks : the Official Journal of the International Neural Network Society, 19(8), 1153-1160.

Dember, W. N. (1956). Response by the rat to environmental change. Journal of Comparative and Physiological Psychology, 49(1), 93.

Dinsmoor, J. A., Mulvaney, D. E., \& Jwaideh, A. R. (1981). Conditioned reinforcement as a function of duration of stimulus. Journal of the Experimental Analysis of Behavior, 36(1), 41-49.

Doll, B. B., Duncan, K. D., Simon, D. A., Shohamy, D., \& Daw, N. D. (2015). Model-based choices involve prospective neural activity. Nature Neuroscience, 18(5), 767-772. http://doi.org/10.1038/nn.3981

Emery, N. J., \& Clayton, N. S. (2004). The mentality of crows: convergent evolution of intelligence in corvids and apes. Science, 306(5703), 1903-1907.

Farovik, A., Place, R. J., McKenzie, S., Porter, B., Munro, C. E., \& Eichenbaum, H. (2015). Orbitofrontal Cortex Encodes Memories within Value-Based Schemas and Represents Contexts That Guide Memory Retrieval. Journal of Neuroscience, 35(21), 8333-8344. http://doi.org/10.1523/JNEUROSCI.0134-15.2015

Gershman, S. J., \& Schoenbaum, G. (2017). Rethinking dopamine prediction errors, 1-20. http://doi.org/10.1101/239731

Gipson, C. D., Alessandri, J. J., Miller, H. C., \& Zentall, T. R. (2009). Preference for 50\% reinforcement over 75\% reinforcement by pigeons. Learning \& Behavior, 37(4), 289-298.

Golman, R., \& Loewenstein, G. (2015). Curiosity, Information Gaps, and the Utility of Knowledge. SSRN Electronic Journal. http://doi.org/10.2139/ssrn.2149362

Golman, R., \& Loewenstein, G. (2016). Information Gaps: A Theory of Preferences Regarding the Presence and Absence of Information.

Gottlieb, J., Oudeyer, P.-Y., Lopes, M., \& Baranes, A. (2013). Information-seeking, curiosity, and attention: computational and neural mechanisms. Trends in Cognitive Sciences, 17(11), 585-593. http://doi.org/10.1016/j.tics.2013.09.001

Gruber, M. J., Gelman, B. D., \& Ranganath, C. (2014). States of Curiosity Modulate Hippocampus-Dependent Learning via the Dopaminergic Circuit. Neuron, 84(2), 486-496. http://doi.org/10.1016/j.neuron.2014.08.060

Harlow, H. F. (1950). Learning and satiation of response in intrinsically motivated complex puzzle performance by monkeys. Journal of Comparative and Physiological Psychology, 43(4), 289.

Harlow, H. F., Harlow, M. K., \& Meyer, D. R. (1950). Learning motivated by a manipulation drive. Journal of Experimental Psychology, 40(2), 228.

Hayden, B. Y. (2016). Time discounting and time preference in animals: a critical review. Psychonomic Bulletin \& Review, 23(1), 39-53.

Hayden, B. Y., \& Platt, M. L. (2007). Temporal Discounting Predicts Risk Sensitivity in Rhesus Macaques. Current Biology, 17(1), 49-53. http://doi.org/10.1016/j.cub.2006.10.055 
Hayden, B. Y., \& Platt, M. L. (2009). The mean, the median, and the St. Petersburg paradox. Judgment and Decision Making, 4(4), 256-272.

Hayden, B. Y., Pearson, J. M., \& Platt, M. L. (2009). Fictive reward signals in the anterior cingulate cortex. Science, 324(5929), 948-950. http://doi.org/10.1126/science.1168488

Hayden, B., Heilbronner, S., \& Platt, M. (2010). Ambiguity aversion in rhesus macaques. Frontiers in Neuroscience, 4, 166.

Heilbronner, S. R., \& Hayden, B. Y. (2013). Contextual factors explain risk-seeking preferences in rhesus monkeys. Frontiers in Neuroscience, 7, 7. http://doi.org/10.3389/fnins.2013.00007

Heilbronner, S. R., \& Hayden, B. Y. (2016). The description-experience gap in risky choice in nonhuman primates. Psychonomic Bulletin \& Review, 23(2), 593-600. http://doi.org/10.3758/s13423-015-0924-2

Howard, J. D., \& Kahnt, T. (2017). Identity-Specific Reward Representations in Orbitofrontal Cortex Are Modulated by Selective Devaluation. Journal of Neuroscience, 37(10), 2627 2638. http://doi.org/10.1523/JNEUROSCI.3473-16.2017

Hughes, R. N. (1968). Behaviour of male and female rats with free choice of two environments differing in novelty. Animal Behaviour, 16(1), 92-96.

Kahnt, T., Heinzle, J., Park, S. Q., \& Haynes, J.-D. (2010). The neural code of reward anticipation in human orbitofrontal cortex. Proceedings of the National Academy of Sciences of the United States of America, 107(13), 6010-6015. http://doi.org/10.1073/pnas.0912838107

Kang, M. J., Hsu, M., Krajbich, I. M., Loewenstein, G., McClure, S. M., Wang, J. T.-Y., \& Camerer, C. F. (2009). The wick in the candle of learning: Epistemic curiosity activates reward circuitry and enhances memory. Psychological Science, 20(8), 963-973.

Kidd, C., \& Hayden, B. Y. (2015). The Psychology and Neuroscience of Curiosity. Neuron, 88(3), 449-460. http://doi.org/10.1016/j.neuron.2015.09.010

Kidd, C., Palmeri, H., \& Aslin, R. N. (2013). Rational snacking: Young childrenâ€ $\mathfrak{T M}_{\mathrm{S}}$ decisionmaking on the marshmallow task is moderated by beliefs about environmental reliability. Cognition, 126(1), 109-114. http://doi.org/10.1016/j.cognition.2012.08.004

Kidd, C., Piantadosi, S. T., \& Aslin, R. N. (2012). The Goldilocks effect: Human infants allocate attention to visual sequences that are neither too simple nor too complex. PLoS ONE, 7(5), e36399.

Kidd, C., Piantadosi, S. T., \& Aslin, R. N. (2014). The Goldilocks effect in infant auditory attention. Child Development, 85(5), 1795-1804.

Kivy, P. N., Earl, R. W., \& Walker, E. L. (1956). Stimulus context and satiation. Journal of Comparative and Physiological Psychology, 49(1), 90.

Langdon, A. J., Sharpe, M. J., Schoenbaum, G., \& Niv, Y. (2018). Model-based predictions for dopamine. Current Opinion in Neurobiology, 49, 1-7.

Lieberman, D. A. (1972). Secondary reinforcement and information as determinants of observing behavior in monkeys (Macaca mulatta). Learning and Motivation, 3(3), 341-358.

Loewenstein, G. (1994). The psychology of curiosity: A review and reinterpretation. Psychological Bulletin, 116(1), 75.

MacKay, D. J. C. (2003). Information Theory, Inference and Learning Algorithms. Cambridge University Press.

Menzel, C. R. (1991). Cognitive aspects of foraging in Japanese monkeys. Animal Behaviour, 4l(3), 397-402.

Noonan, M. P., Walton, M. E., Behrens, T. E. J., Sallet, J., Buckley, M. J., \& Rushworth, M. F. S. (2010). Separate value comparison and learning mechanisms in macaque medial and lateral 
orbitofrontal cortex. Proceedings of the National Academy of Sciences of the United States of America, 107(47), 20547-20552. http://doi.org/10.1073/pnas.1012246107

Oudeyer, P.-Y., Kaplan, F., \& Hafner, V. V. (2007). Intrinsic motivation systems for autonomous mental development. IEEE Transactions on Evolutionary Computation, 11(2), 265286.

Pearson, J. M., Hayden, B. Y., Raghavachari, S., \& Platt, M. L. (2009). Neurons in Posterior Cingulate Cortex Signal Exploratory Decisions in a Dynamic Multioption Choice Task. Current Biology, 19(18), 1532-1537. http://doi.org/10.1016/j.cub.2009.07.048 external reinforcement. Journal of Comparative and Physiological Psychology, 49(2), 131.

Purdy, J. E., \& Peel, J. L. (1988). Observing response in goldfish (Carassius auratus). Journal of Comparative Psychology (Washington, D.C. : 1983), 102(2), 160.

Roper, K. L. E. A. (1999). Observing Behavior in Pigeons: The Effect of Reinforcement Probability and Response Cost Using a Symmetrical Choice Procedure, 1-20.

Rosati, A. G., \& Hare, B. (2013). Chimpanzees and bonobos exhibit emotional responses to decision outcomes. PLOS ONE, 8(5), e63058.

Sadacca, B. F., Wied, H. M., Lopatina, N., Saini, G. K., Nemirovsky, D., \& Schoenbaum, G. (2018). Orbitofrontal neurons signal sensory associations underlying model-based inference in a sensory preconditioning task. eLife, 7, e30373.

Shannon, C. E., \& Weaver, W. (2015). The mathematical theory of communication.

Sleezer, B. J., Castagno, M. D., \& Hayden, B. Y. (2016). Rule encoding in orbitofrontal cortex and striatum guides selection. Journal of Neuroscience, 36(44), 11223-11237.

Stagner, J. P., \& Zentall, T. R. (2010). Suboptimal choice behavior by pigeons. Psychonomic Bulletin \& Review, 17(3), 412-416.

Stalnaker, T. A., Liu, T.-L., Takahashi, Y. K., \& Schoenbaum, G. (2018). Orbitofrontal neurons signal reward predictions, not reward prediction errors. Neurobiology of Learning and Memory.

Steiner, J. (1967). Observing responses and uncertainty reduction. The Quarterly Journal of Experimental Psychology, 19(1), 18-29.

Strait, C. E., Blanchard, T. C., \& Hayden, B. Y. (2014). Reward value comparison via mutual inhibition in ventromedial prefrontal cortex. Neuron, 82(6), 1357-1366. http://doi.org/10.1016/j.neuron.2014.04.032

Takahashi, Y. K., Batchelor, H. M., Liu, B., Khanna, A., Morales, M., \& Schoenbaum, G. (2017). Dopamine neurons respond to errors in the prediction of sensory features of expected rewards. Neuron, 95(6), 1395-1405. e3.

Thorndike, E. (2017). Animal intelligence: Experimental studies.

Tolman, E. C. (1948). Cognitive maps in rats and men. Psychological Review, 55(4), 189.

Vasconcelos, M., Monteiro, T., \& Kacelnik, A. (2015). Irrational choice and the value of information. Scientific Reports, 5, 13874.

Walton, M. E., Behrens, T. E. J., Buckley, M. J., Rudebeck, P. H., \& Rushworth, M. F. S. (2010). Separable learning systems in the macaque brain and the role of orbitofrontal cortex in contingent learning. Neuron, 65(6), 927-939. http://doi.org/10.1016/j.neuron.2010.02.027

Wang, M. Z., \& Hayden, B. Y. (2017). Reactivation of associative structure specific outcome responses during prospective evaluation in reward-based choices. Nature Communications, 8 , 15821. http://doi.org/10.1038/ncomms15821

Whittle, P. (1988). Restless bandits: Activity allocation in a changing world. Journal of Applied 
$634 \quad$ Probability, 25(A), 287-298.

635 Wilton, R. N., \& Clements, R. O. (1971). Observing responses and informative stimuli. Journal

636 of the Experimental Analysis of Behavior, 15(2), 199-204.

637 Wyckoff, L. B., Jr. (1952). The role of observing responses in discrimination learning. Part I.

$638 \quad$ Psychological Review, 59(6), 431.

639 Zentall, T. R., \& Stagner, J. (2011). Maladaptive choice behaviour by pigeons: an animal ana-

640 logue and possible mechanism for gambling (sub-optimal human decision-making behav-

641 iour). Proceedings of the Royal Society B: Biological Sciences, 278(1709), 1203-1208. 
Figure 1

1A. The Counterfactual Information Task.

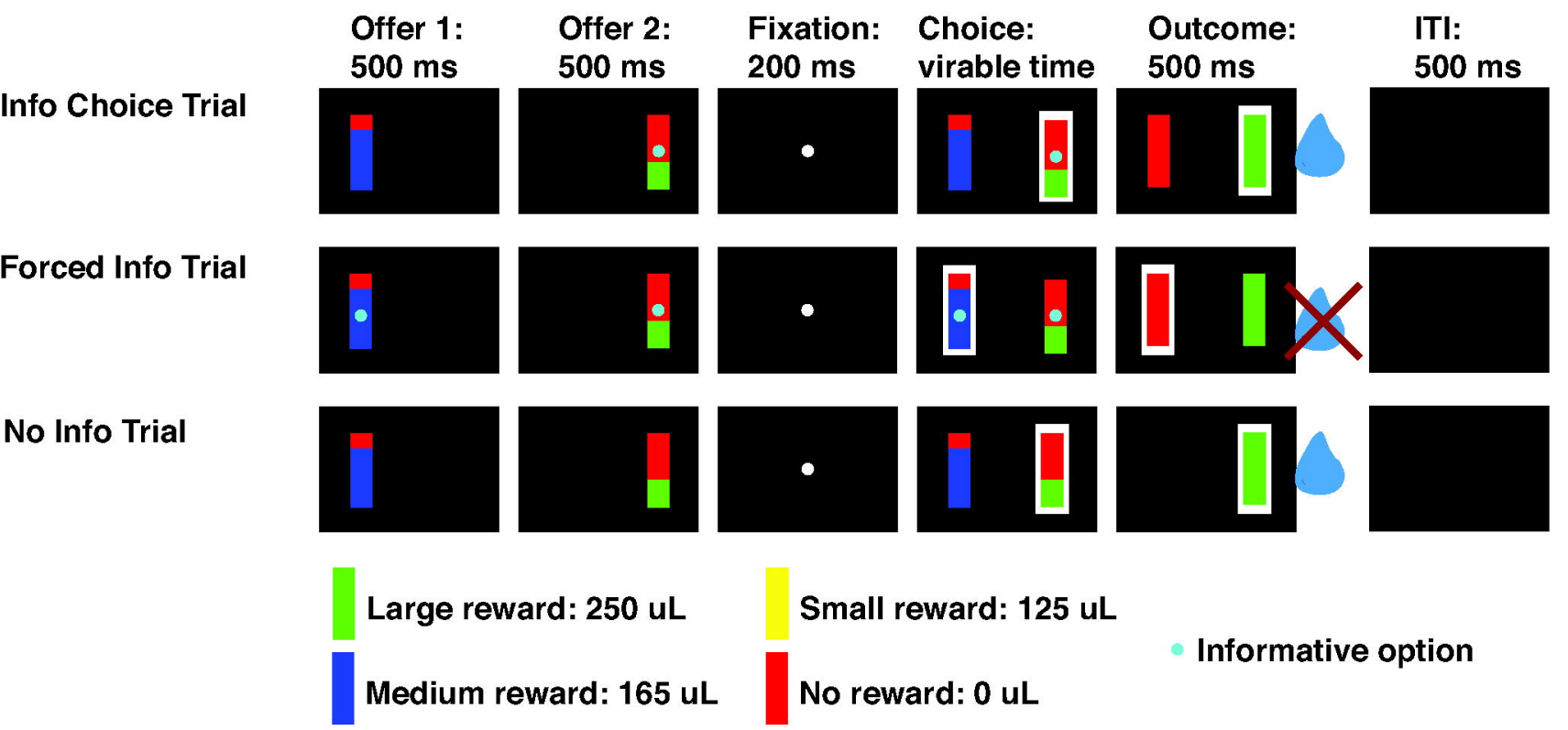

1B. Entropy of Probablistic Outcomes.

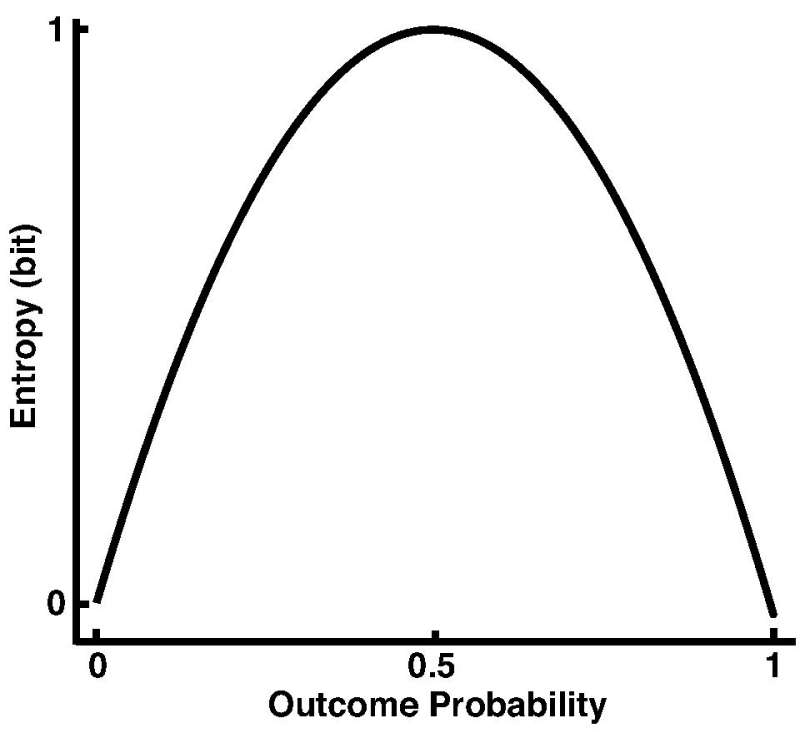




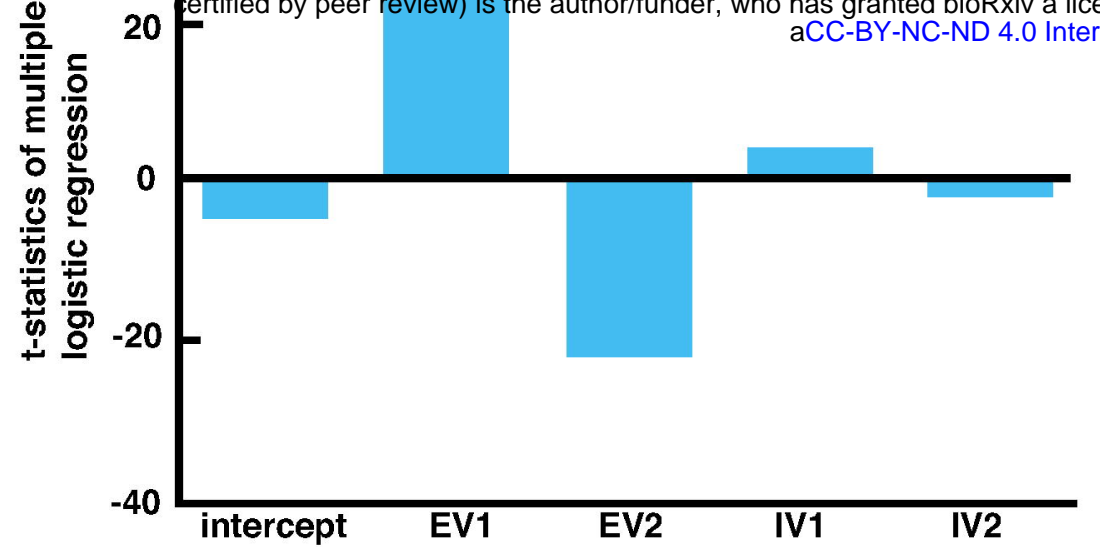

\section{G. Informational Value not Visual Stimuli Predicts Choice.}

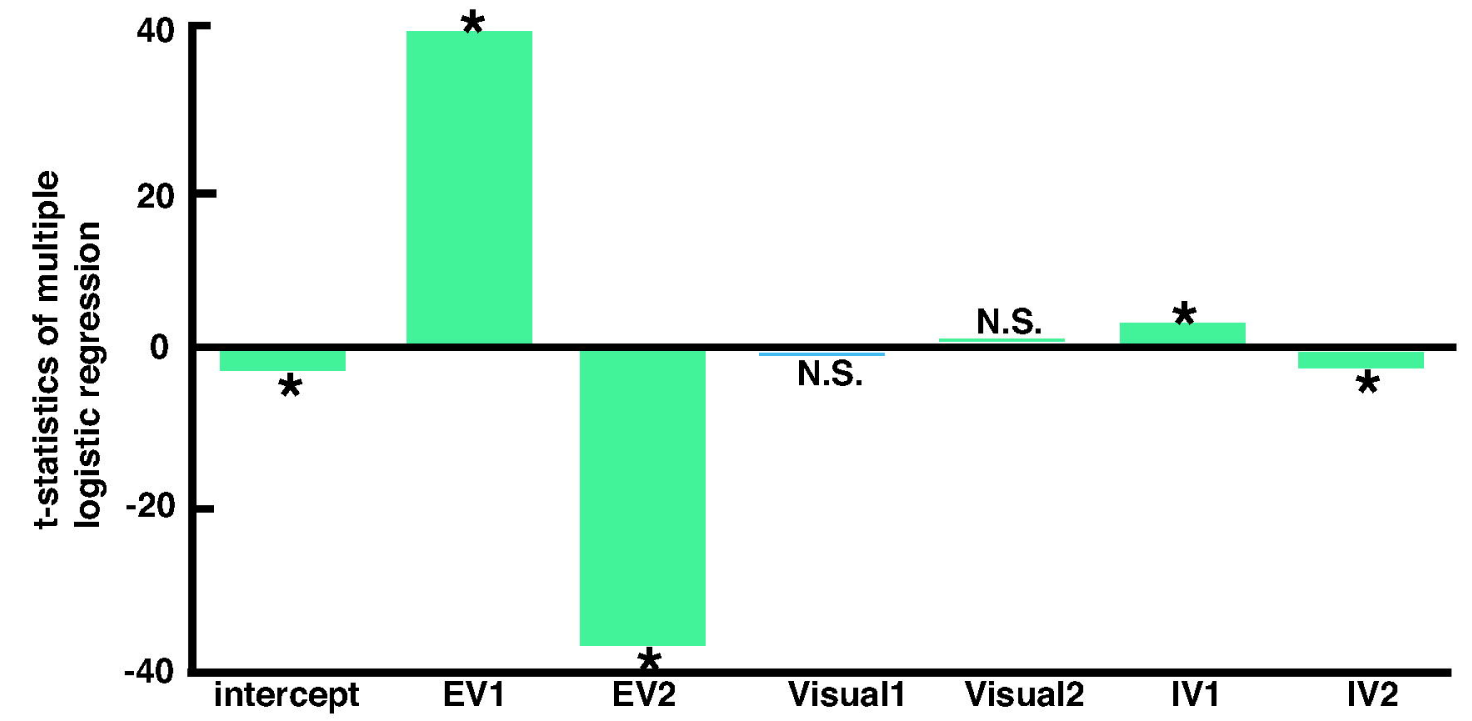

\section{H. Counterfactual Information Was Subjectively Valuable.}

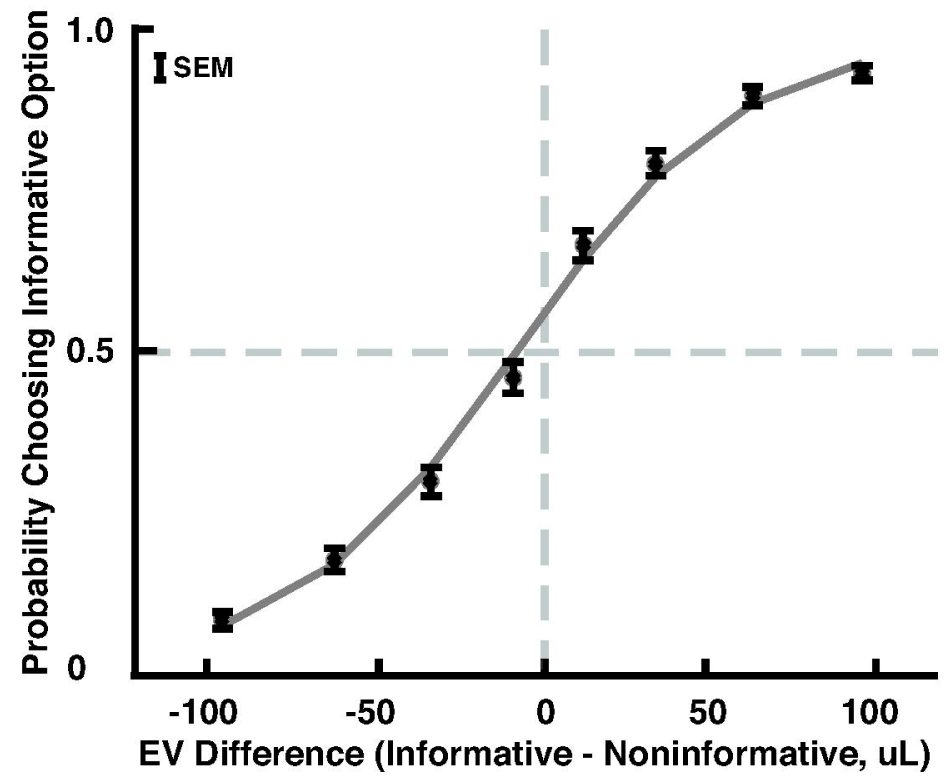

